\title{
Liquid Phase Dispersion/Mixing Investigation in Gas-liquid Upflow Moving Bed Hydrotreater Reactor(MBR)
}

\author{
Vineet Alexander ${ }^{1}$, Hamza Albazzaz ${ }^{2}$, and Muthanna H Al Dahhan ${ }^{1}$ \\ ${ }^{1}$ Missouri University of Science and Technology \\ ${ }^{2}$ Kuwait Institute for Scientific Research
}

May 13, 2020

\begin{abstract}
Liquid phase dispersion/mixing studies have been performed for the first time on the catalyst bed of a cold flow scaled-down upflow moving bed re- actor (MBR) using residence time distribution (RTD) at various flow rates including the scaled down condition. MBR is hydrotreater and its design includes catalyst bed with conical bottom and plena. The catalyst bed is modeled using Wave Model, and its mixing parameters are estimated using a mathematical approach based on convolution and regression. A study is also shown to illustrate the limitation of Axial Dispersion Model (ADM) while modeling the flow which noticeably deviates from plug flow. In addition, a dimensionless variance is also estimated for the bed region from the RTDs. Overall liquid dispersion/mixing is seen high in MBR, with more disper- sion/mixing in the expanded bed region. Scaled down conditions are seen best when considering the overall catalyst utilization and liquid mixing for hydrotreatment.
\end{abstract}

\section{Hosted file}

04.09.20.Liquid_tracer_Elesevier double space.pdf available at https://authorea.com/users/ 321674/articles/450890-liquid-phase-dispersion-mixing-investigation-in-gas-liquidupflow-moving-bed-hydrotreater-reactor-mbr 